\title{
Endotracheal Intubation Done in Field Conditions of Restrained Space
}

\author{
S. Gavrilovićc ${ }^{1}$ S. Milić ${ }^{2}$ F. Dujmović ${ }^{3}$, Z. Fišer ${ }^{4}$ \\ ${ }^{1}$ Clinic of Anaesthesiology and Critical Care Medicine, Clinical Center of Vojvodina, Novi Sad, Serbia \\ ${ }^{2}$ Department of Emergency Medicine, Health Centre of Indjija, Serbia \\ ${ }^{3}$ Institute of Patophysiology, Clinical Center of Vojvodina, Novi Sad, Serbia \\ ${ }^{4}$ Emergency Medicine Service, Novi Sad, Serbia
}

\begin{abstract}
Endotracheal intubation used as a method of cardiopulmonal resuscitation and advanced life support in a field condition frequently represents a problem even to very experienced resuscitatiors because of its extremly complex circumstances. The author's aim of this work is to suggest his own way of the patient's intubation in a field condition by the application of the method which has not been described in the literature yet. A several dozen of patients have been intubated by this method in such conditions which did not represent even the minimum for intubation done in a conventional way, but they were enough to prove our method. Maximum performing time for the sample was 15 seconds. We consider that, using this method, the endotracheal intubation can be realized in all conditions up to now thought untouchable. This method requires only 30 to $35 \mathrm{~cm}$ wider space than patient's shoulders occupate and 20 to $30 \mathrm{~cm}$ extra of his height. The only noted inadequacy is the risk in spine injury intubation, but with more careful treatment it can be avoided. Key words: Endotracheal intubation, cardiopulmonal resuscitation, field condition, restrained space.
\end{abstract}

Endotracheal intubation (EI), as a part of resuscitation procedure, represents a method which enables artificial (or spontaneous) respiration. Laryngoscope application makes it possible for resuscitator to place endotracheal tubus into trachea in order to provide free airway. Furthermore, EI helps in removing all substances (blood, mud, vomited matter, parts of dental prosthesis etc) which can obstruct airways and disable ventilation process $[1,3]$. Artificial ventilation is performed in cases of apnea or nonstabile spontaneous respiriltion. Depending on technical basis and patient condition, high percentage of oxygen is recommended in ambuballoon treatment. Due to usually extremely complex circumstances in field conditions (low accessibility, restricted manipulation) it is often hard, not only to accomplish EI in the ordinary way, but even to place laryngeal mask or endoesophageal tubus [2, 10, 12]. The objective of this paper is to suggest a new technique of EI which can be done in field conditions of restrained space as well as in «normal» conditions [12]. This method hasn't been described in professional literature yet, but it was confirmed in our praxis. This method has also been acepted and it is used by emergency medical systems worldwideMunchen, Zagreb, Otava etc [3, 12].

\section{Materials and Methods}

When patient is lying on his back (Photograph I), righthanded resuscitator takes position on the left side of his lumbal region, while kneels on the right knee and holds onto left foot. Resuscitator turns over the patient's body onto right side, puts his right knee next to patient's right scapula and, as holds patient's left shoulder, he pulls and sets both patient's shoulders on the inner side of his right upper leg. Manipulating by laryngoscope in the left hand, resuscitator performs EI in the in anatomically complicated cases (short neck or extreme obesitas). According to our experi-

Адрес для корреспонденции (Correspondence to):

Sava Gavrilović

E-mail: milkens@sbb.rs ence, visibility of larynx is complete although this method demands only $20-30 \mathrm{~cm}$ above patient's head, and the same space from the left side.

After fixing an endotracheal tubus, resuscitator slowly raises patient's shoulders in order to release upper leg and to continue resuscitation. Regarding to hard support of resuscitator's thigh underneath patient's chest, it's posssible to do adequate heart massage all the time.

When patient is lying on the stretcher (Photograph 2), resuscitator takes hold of his shoulders and puts him in the sitting position. While resuscitator supports patient's back by left hand, he simultaneously takes a semi-lying position on the stretcher, behind the patient. This position is identical to the onset position when patient is lying on his back. Next step is to set patient's scapulas on the resuscitator's inner side of the right upper leg, and to accomplish EI in the same way as in the first case. EI performed on the stretcher could also be done when patient is lying on the bed, in the inappropriate transport vehicle, as well as in enormously narrow spaces.

\section{Results and Conclusions}

In urgent medicine, there are several indications for EI such as: respiratory/cardiac arrest (or insufficiency), heavy polytraumas, external or internal bleeding followed by blood loss higher than $20 \%$ of circulatory volume [4, 9 , 10]. The necessity of immediate action at the scene of incident means that EI must be done at the places often unreachable for ambulance and on the various surfaces like: send, mud, concrete, snow, soil overgrown with high grass or grain etc $[2,10,11]$. Anyway, the most difficult places for EI are small flats where is impossible to start resuscitation without moving the furniture. These limiting circumstances impose a need for appropriate EI technique, usable under the roughest conditions [3, 5]. Our method has been applied by some of the staff in Urgent Medical Help Service, but it tends to become a simple professional routine there. Common feature for all accomplished interventions is that EI was performed in such conditions which did not represent even the minimum for intubation done in a conventional way $[6,8]$. The shortest performing time at 


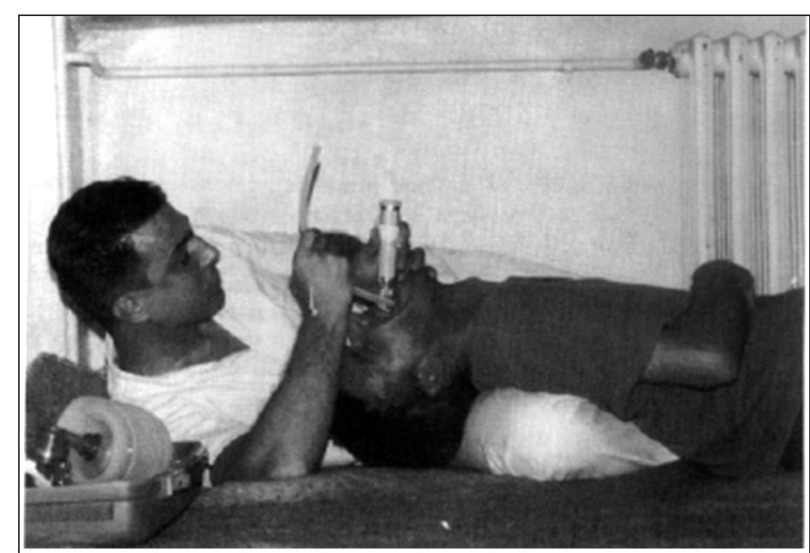

Fig. 1. El when patients is lying on his back.

the scene for our technique was 8 seconds, and the longest about 15 seconds. In praxis we noticed a lot of benefits in favor of our method over conventional way of EI such as:

- larynx is about $15 \mathrm{~cm}$ above the level of pylorus, so gastric content can't; be poured out passively;

- for the purpose of cleaning the upper airways, proposed position provides complete visibility and undisturbed work;

- muscular strenght of the upper leg, even for physically weaker resuscitators, allows easy manipulating with obese and large patients in order to set an optimal position for placing the endotracheal tubus;

- characteristic arm position in this technique makes it possible for the resuscitator to handle a laryngo-

\section{Литература}

1. Lalević P. Anesteziologija. Beograd: Savremena administarcija; 1993.

2. Fišer Z., Gavrilovć $S$., Sečen $S$. et al. Teško obezbedivanje disajnog puta. Medicina danas 2002; 1 (1-2): 151-156.

3. Jovanović L., Milić S., Petrović $V$. Endotracheal intubation under field condition. Medicina danas 2008; 7 (4-6): 173-180.

4. Birkinshaw R., McKinnon K. A., Kitching G., Ryan B. Intubation in difficult positions. Prehosp. Immed. Care 1998; 2: 59-62.

5. Koetter K. P., Hilker T., Genzwuerker V. H. et al. A randomized comparison of positions for intubation on the ground. Prehosp. Emerg. Care 1997; 1 (2): 96-99.

6. Lavery G. G., McCloskey B. Airway management. In: Patient Centred Acute Care Training (PACT). Roessler M., Fluit L., Ramsay G. (eds.). Brussels: European Society of Intensive Care Medicine; 2003. 1-27.

7. O'Connor R. E., Rubinstein H. Failed prehospital intubations: An analysis of emergency department courses and outcomes. Prehosp. Emerg. Care 2001; 5 (2): 134-141.

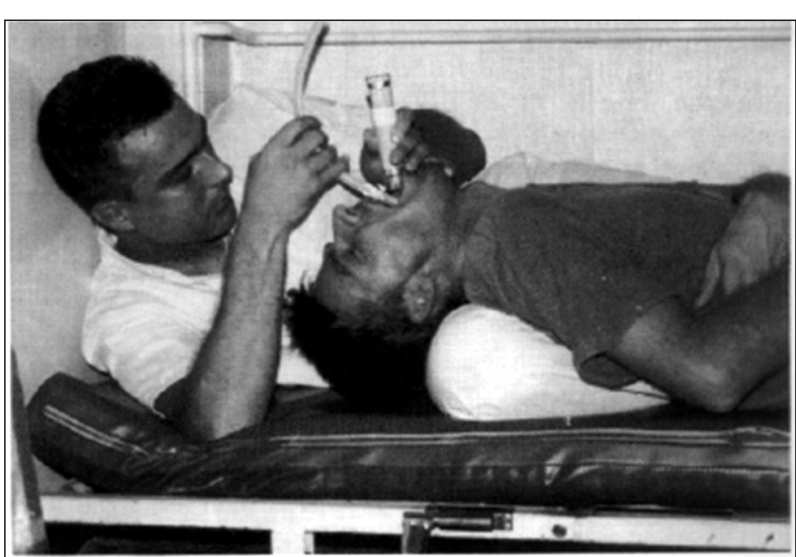

Fig. 2. El when patients is on the stretcher.

scope easily, without fatigue typical for full-extended arm position in conventional EI;

- resuscitator has an absolute visibility of larynx during EI;

- diverse field conditions do not affect on performing time;

- only one resuscitator is enough for the procedure.

According to full larynx visibility in this method, possible complications in placing of endotracheal tubus are being avoided. With our system, EI in field conditions has been made considerably easier and applicable in wide range of circumstances. For the further period we hope to confirm indications that our method of EI could be performed even in the sitting position.

8. Reynolds S. F., Heffner J. Airway management of the critically ill patient: rapid-sequence intubation. Chest 2005; 127 (4): 1397-1412.

9. Davis D., Hoyt D., Ochs M. et al. The effect of paramedic rapid sequence intubation on outcome in patients with severe traumatic brain injury. J. Trauma 2003; 54 (3): 444-453.

10. Ovassapian A., Meyer R. Airway Management. New York; 2002.

11. Practice guidelines for management of the difficult airway: An updated report by the American Society of Anesthesiologists Task Force on management of the difficult airway. Anesthesiology 2003; 98 (5): 1269-1277.

12. Fišer Z., Gavrilovć S., Petaković G. et al. Urgentna endotrahealna intubacija direktnom laringoskopijom. Medicina danas 2002; 1 (1-2): $140-150$.

Поступила 03.03.10 